\title{
Complementary logics of target setting: hierarchist and experimentalist governance in the Scottish National Health Service
}

L K Schang and A Morton

\section{Abstract}

Where policy ends are contested and means for change are ambiguous, imposing central targets on local organisations - what we call hierarchist governance - is problematic. The concept of experimentalist governance suggests that target-setting should rather be a learning process between central regulators and local organisations. However, the relationship between experimentalist and hierarchist governance remains unclear. Existing literature suggests that the learning-oriented experimentalist logic is hard to reconcile with a hierarchist logic focussed on accountability for results. We examine whether complementary use of hierarchist and experimentalist ideas is possible. Drawing on experiences from Scotland, we find that experimentalist and hierarchist logics can co-exist in the same performance management system. Each logic served distinct roles with respect to target-setting, implementation and accountability. The emphasis on experimentalism was stronger where ends and means were contested (the case of shifting the balance of care for older people) than where both ends and means seemed obvious initially (the case of healthcare-associated infections, where targetsetting followed a more hierarchist logic). However, governance drifted towards experimentalism when rising rates of community-acquired infections decreased clarity about effective interventions. The nature of policy issues and changes therein over time appear to be important conditions for synergies between governance logics. 


\section{Introduction}

Targets are used in many health systems to focus managerial attention on priority areas for improvement and, by providing an explicit standard for evaluation, to promote accountability for results (Wismar et al., 2008, Smith and Busse, 2010). However, the top-down imposition of targets by central government on local organisations has attracted criticism (Carter, 1989, Bevan and Hood, 2006). This form of governance by targets - what we call hierarchist governance - requires 'dials' (Carter, 1989): accurate measures of performance which unambiguously represent desired policy ends (Bevan and Hood, 2006) and whose means of attainment are available to the organisations under scrutiny (Jacobs et al., 2006). For many issues in health policy, however, goals are contested and means for change are ambiguous. For such 'wicked' problems (Rittel and Webber, 1973), performance indicators are mere 'tin openers': measures which 'do not give answers but prompt interrogation and inquiry, and by themselves provide an incomplete and inaccurate picture' (Carter, 1989, p. 134).

The concept of experimentalist governance (Sabel and Zeitlin, 2012) suggests that when the 'correct' targets and means for change are ambiguous, targetsetting should rather be conceptualised as a learning process between central and local organisations. However, the relationship between experimentalist 
and hierarchist governance is still unclear (Fossum, 2012). The wider performance management literature has questioned the extent to which measurement for learning and improvement can be fostered alongside demands for accountability for results (Freeman, 2002), suggesting these logics are incompatible. This study, in contrast, examines the potential for complementarity of hierarchist and experimentalist governance, in the sense that they align and add value to each other. We investigate two research questions:

1. Can hierarchist and experimentalist elements co-exist and complement each other in the same healthcare target system?

2. Does the relative emphasis on experimentalist as opposed to hierarchist logics differ between policy issues depending on the degree of perceived ambiguity over ends and means?

This study contributes to knowledge as follows. First, we examine a system (the $\underline{\text { Scottish HEAT target system) whose socio-historical context is favourable to }}$ any potential complementarity between hierarchism and experimentalism. As McDermott et al. (2015) suggest, a precondition for such complementarity includes long-standing collaborative relationships between central and local organisations within a hierarchically administered health system. As we describe in section 3.1., the Scottish HEAT target system meets these conditions. Second, we follow-up on Sabel and Zeitlin's (2012) hypothesis that experimentalism will evolve for policy issues whose ends and means are 
ambiguous. In turn, where ends and means are relatively clear, a more

hierarchist approach may serve to foster common standards of practice. While existing research has shown between-country differences in target-based governance (Wismar et al., 2008, Blackman et al., 2009, Bevan, 2010), we find that within-country variations in governance style exist at the level of policy issues.

The next section contrasts theoretical assumptions underpinning hierarchist and experimentalist governance, reviews the rationale for exploring the scope for complementarity between them, and highlights potential barriers to complementariy. In the empirical analysis, we compare the development of targets for two policy issues in the Scottish HEAT target system. Implications for policy and research are discussed.

\section{Theoretical and policy background}

\subsection{Setting targets: Hierarchist versus experimentalist governance}

Drawing on principal-agent theory, hierarchist target-setting (Table 1) became a key policy instrument under New Public Management reforms pursued in various countries since the 1980s (Hood, 2007). It is vividly illustrated by the model of 'targets and terror' (Bevan and Hood, 2006) adopted by the English Labour Government between 2001 and 2005 where public sector organisations were subject to strict performance targets with severe consequences for failure. 
Experimentalist governance (Sabel and Zeitlin, 2012; Table 1) has evolved as a critique of the assumptions underlying the hierarchist perspective (Table 1) in parallel to calls for more deliberation in public management (e.g. Barzelay, 1992, Hood and Jackson, 1994). Conceived as a 'learning process', experimentalist governance links four elements in an iterative cycle: (i) Centre and local actors agree on broad goals and metrics to ascertain their achievement; (ii) local actors pursue these goals in their own way while the Centre provides support; (iii) local actors report their performance regularly, engage in peer review and share learning about 'what works'; (iv) affected actors periodically revise goals and means following the results of the review process (Sabel and Zeitlin 2012, p. 170).

Experimentalist governance was developed to understand how multilevel governance structures in uncertain and heterogeneous contexts can improve performance. This includes complex regulatory settings such as child protective services (Noonan et al., 2009) and policy-making in the European Union on areas such as social protection, telecommunications, drug and food safety where the interdependency of member states, the European Commission and other stakeholders often precludes formal rule-making (Sabel and Zeitlin, 2008, Fierlbeck, 2014). In these contexts, the increasing use of 'open norms' (broad objectives and high level regulatory principles) reflects the need to avoid clear and precise rules in order to deal with regulatory uncertainty (Hocepied and de Streel, 2005). 


\subsection{Why explore the scope for complementarity between hierarchist and}

experimentalist governance?

Complementarity implies that certain entities (here, logics of target-setting) come together in a synergistic way. Since each logic retains its essential characteristics, complementarity is thought to enable a broader spectrum of policy responses (Fischer and Ferlie, 2013) and to balance the limitations of a single model only (Goddard et al., 2000). Below we review key limitations of hierarchist governance with respect to target-setting, implementation, and accountability. We highlight why experimentalism may offer an effective complement but not necessarily a substitute.

With regard to target-setting, where ideal ends of policy are contested, experimentalist governance scholars claim that argument offers a better basis for decision-making than authority (Pires, 2011). Because local organisations have an insight into frontline problems that national oversight bodies lack, it is argued that 'global and local knowledge are mutually corrective, not hierarchically ordered' (Sabel, 2004, p. 181). However, insofar as governments have a legitimate mandate to define priorities (Mays, 2006, Smith and Busse, 2010), the experimentalist proposal of joint target-setting seems to contradict existing lines of accountability between government and subordinate administrations. Thus, while the engagement of local stakeholders, as called for by experimentalist governance, may be a valuable or even an essential strategy 
to develop targets for 'wicked' problems, it may not be desirable to abandon hierarchist stewardship of the system entirely.

Where means for implementation are ambiguous, the hierarchist approach provides no process how to achieve targets. Consequently, local organisations tend to develop various coping strategies (Lawton et al., 2000) but there is not necessarily an attempt to share learning across contexts. Experimentalist governance addresses this limitation by promoting local 'experiments' and mutual exchange about different approaches taken, so as to identify and scaleup good practice (Sabel and Zeitlin, 2012). However, where effective interventions are known or become clearer over time (e.g. after a period of deliberative learning), regulatory authorities can codify and enforce common standards of practice, subject to dynamic revision. Hierarchist regulation thus retains a key role (Eberlein 2010).

In terms of accountability, the hierarchist view of accountability for results implies the need to comprehensively specify goals. Since most public services have multiple goals, incomplete contracts combined with divergent interests and informational asymmetries risk encouraging gaming by local organisations (Bevan and Hood, 2006) and misinterpretation of complex local production processes by regulators (Smith, 1995). In search of complete contracts, reforms in England and the Netherlands have led to a multiplication of quantitative indicators so as to cover 'every' aspect of performance, thereby overwhelming the capacities of central and local organisations (Power, 1999, Pollitt et al., 2010). Experimentalism, in contrast, is seen to limit the need for a variety of 
indicators since it strives to understand how targets are implemented (Noonan et al. 2009; Sabel and Zeitlin, 2012). Nevertheless, within a publicly funded health system, ignoring demands for accountability for results in efforts to improve performance seems unrealistic (Ernst et al., 2008).

The above review suggests that hierarchist and experimentalist governance have different potential strengths and limitations with respect to target-setting, implementation and accountability. Thus, there is a strong rationale to explore the scope for complementarity between them.

\subsection{Barriers to complementarity}

Is complementarity between hierarchist and experimentalist governance empirically feasible? The wider healthcare performance management literature has tended to argue that 'measurement for improvement' (which underpins experimentalist governance) ought to be kept separate from 'measurement for accountability for results' (which underlies hierarchist governance). While the former is thought to require a culture of openness, using data that is good enough to diagnose and remedy problems, the latter is premised on a culture of judgment against fixed objectives, with a consequent need for accurate data (Solberg et al., 1997, Freeman, 2002, Davies, 2005).

Such incompatibility of both logics, in the sense that regulators adopt either one or the other logic, but not elements of both, seems to be supported by empirical research on health targets. An international review of health targets in seven 
European nations found that target-setting styles differed in terms of their focus on either hierarchist regulation and accountability, or more deliberative, learning-oriented stakeholder engagement (Ernst et al., 2008). The findings showed struggles in bringing these elements together: some nations fostered stakeholder consensus, but failed to achieve accountability (e.g. Germany, Flanders) while others established strong regulatory frameworks focussed on accountability for results yet omitted local ownership (e.g. England) (Ernst et al., 2008).

However, it is not known to what extent these findings reflect a general incompatibility between these approaches to target governance, or specific features of the health systems examined.

\section{Methods}

\subsection{System context and study design}

Scotland offers a suitable context to examine experimentalist governance ideas within a hierarchical system. The planning and delivery of health services is delegated to 14 territorial NHS Boards who are responsible for $£ 10.9$ billion (of $£ 11.9$ billion Government spending on health in 2012/13; Audit Scotland (2013). But while NHS Boards are major budget-holders and have considerable powers to shape patterns of service delivery, they remain directly accountable to Scottish ministers and subject to central constraints such as the requirement to break even in each financial year (Steel and Cylus, 2012). 
The model of governance of the Scottish NHS immediately after devolution in 1999 has been described as one of trust and altruism since local organisations were trusted to deliver a high-quality service (Bevan et al., 2014). Ministers have long eschewed targets or rankings that inflict reputational damage, rejecting top-down performance management in favour of a consensual approach with local managers and clinical leaders (Greer, 2004). The relational distance between central and local organisations is low (Hood, 2007). Senior managers from the different regions 'meet regularly and have easy access to ministers and officials in the Scottish Government' (Steel and Cylus 2012, p. 26).

Targets for territorial Boards were first introduced in 2002, in the form of the Performance Assessment Framework (PAF) (Scottish Executive Health Department 2003). The exact number of targets was perceived to be opaque as the PAF referred to multiple policy frameworks; estimates range between a hundred and over two hundred targets. An evaluation concluded that there was an 'overload from the data collection (...) and the risk that PAF might become an end in itself' since it lacked incentives for Boards to improve and share good practice (Farrar et al., 2004).

This changed in 2006 when, as Steel and Cylus state, '[u]nfavourable crossborder comparisons (...) about performance, particularly on waiting times' (2012, p. 113) and a change in minister led to the introduction of a 'tougher and more sophisticated approach to performance management' (2012, p. 114); known as the HEAT (Health improvement, Efficiency, Access and Treatment 
appropriateness) target system. Within a hierarchical yet consensual context, this system offers a suitable context to investigate the potential complementarity of hierarchist and experimentalist governance (our first research question).

To examine the balance between hierarchist and experimentalist logics contingent on the nature of the policy issue (our second research question), we compare the development of HEAT targets for two policy issues. These policy issues were selected based on two criteria. The first criterion was to represent opposite ends on a spectrum of ambiguity over goals and means (Table 2).

- For the case of healthcare-associated infections (HAI), where both ideal performance and the means for change were relatively well-known when targets were introduced, one would expect a more hierarchist logic.

- For the case of shifting the balance of care for older people (SBC), where both the ideal ends and the means for change were ambiguous, one would expect a more experimentalist logic.

Table 2 about here

The second criterion for selecting these two policy issues is methodological: Targets were introduced in 2006 (SBC) and 2008 (HAI) and have evolved since then, thus enabling a comparison of their development over time. 


\subsection{Data collection and analysis}

The study triangulates multiple sources of data (Table 3). Interviewees were recruited following a purposive strategy (Patton, 2002) intended to (i) capture national and local experiences and (ii) represent diverse local contexts. We started with an initial group of national and local managers and, using 'snowballing', invited 33 people for interview. We included Boards from rural and remote areas (e.g. Highlands) and urban areas (e.g. Lothian); small Boards (e.g. Shetland, with a population of less than 20,000) and large Boards (e.g. Glasgow, with a population of over 1 million); and Boards who performed comparatively well and poorly on targets for the two policy issues, since we expected these aspects to potentially influence the perception of targets.

In total, 31 interviews were conducted between June 2014 and February 2015 (two people declined due to time constraints), audio-recorded and transcribed. We considered data saturation to be achieved when no new themes emerged after a couple of further interviews (Guest et al., 2006). Participants were informed about the aims of the study, encouraged to ask questions and assured of the anonymity of their responses. The first author's institutional review committee granted ethics approval.

Based on the theoretical constructs from hierarchist and experimentalist governance, directed content analysis (Hsieh and Shannon, 2005) was used. This enabled theory triangulation as each case was examined through different theoretical lenses (Patton, 2002). The first author collected and analysed the 
data (using NVivo). The second author supervised this process and, through regular discussions, contributed to the iterative refinement of the interpretations. To mitigate against misinterpretation, we shared the findings with the interviewees who were asked to point out any factual errors.

Table 3 about here

\section{Findings}

The next sections analyse the HEAT target system and special features in the governance of HAI and SBC. Specifically, we investigate how approaches to target-setting, implementation and accountability, introduced above, reflect hierarchist or experimentalist logics (for a summary, see Table 4).

Table 4 about here

\subsection{The HEAT target system: Commonalities across targets}

\subsubsection{Target-setting}

The choice of HEAT targets is informed by consultations with service user groups, professional associations and NHS Boards. Some targets arise from political manifesto commitments. Three explicit criteria exist for selecting HEAT targets: (i) alignment with Government priorities; (ii) availability of baseline data; and (iii) scope for implementation by NHS Boards. Each target runs over three years, after which feedback meetings with NHS managers, health 
professionals and Government officials enable the revision or abolition of targets. While the Scottish Government decides on targets (reflecting the hierarchist logic), stakeholders discuss areas where targets add value or cause problems (reflecting the experimentalist logic).

\subsubsection{Implementation}

The HEAT target process is led by a Directorate in the Scottish Government which agrees local delivery plans (LDPs) with each Board and monitors progress against these. In LDPs, Boards explain how they plan to attain the HEAT targets and the risks they face. A head of performance noted that 'LDPS are a way to sensecheck with the Scottish Government and raise concerns we see locally'. This reflects the experimentalist logic insofar as LDPs may serve as a mechanism to help uncover local problems and management strategies. Nevertheless, LDPs are drafted in relation to national guidance and signed-off by the Government. Interviewees perceived LDPs primarily as the 'contract' between Government and Boards, reflecting a hierarchist orientation.

\subsubsection{Accountability}

The HEAT target system has institutionalised two routes to assure accountability. One is a summative assessment that reflects the hierarchist logic of accountability for results. The Government examines progress against the LDPs at Annual Reviews. In addition, biennial Accountability Reviews are held by ministers where members of the public can ask questions. These reviews result in a letter from the Cabinet Secretary about issues Boards are expected to address. National progress against the HEAT targets is reported publicly on the 
Government's website Scotland Performs. There are no financial sanctions or forced redundancies when targets are not met.

The other route is a formative assessment that reflects the experimentalist view of accountability as valid processes. This takes the form of Mid-Year reviews to gauge if Boards are 'on track'. Pressure for corrective action can be escalated through several mechanisms. At monthly meetings of Board Chief Executives with the NHS Chief Executive, performance is routinely discussed. Regular bilateral meetings take place between performance managers from the Scottish Government and Board staff. If there are concerns about a major failure, the Scottish government sends a performance support team to Boards to identify problems and remedial actions. However, interviewees highlighted a constant tension in the teams' dual role of providing support and exercising Government control:

'Boards don't have a choice (...) they must develop an action plan that is heavily scrutinised by the Scottish Government' (Government official).

'The process is not comfortable (...) but from my experience it has been respectful and positive to diagnose problems we had (...) showing how other organisations solve them' (senior manager).

Government officials and local managers pointed out that accountability for results was a response to perceived opacity of the PAF. However, because this evolved within a broader context of public sector reform which emphasised the 
value of partnership (see e.g. the report of the Commission on the Future Delivery of Public Services (2011)), there was also an increasing commitment by the Government to listen to local feedback. Below we explore these themes further with regard to HAI and SBC.

\subsection{Healthcare-associated infections: the quest for zero infections}

\subsubsection{Policy context}

The issue of HAIs climbed the policy agenda in 2008 when an outbreak of clostridium difficile (CDI) at the Vale of Leven hospital resulted in a major revision of infection control practices. The Scottish Government's HAI Taskforce set out a multifaceted approach to change, funded with $£ 56$ million for three years across five areas (HAI Taskforce, 2008): standards of practice; culture (resulting e.g. in a national hand hygiene campaign); education (e.g. on antibiotic prescribing); surveillance and audit (e.g. since 2009, the Healthcare Environment Inspectorate has carried out regular audits of compliance with national standards); and changes in the physical environment and processes (e.g. the introduction of MRSA screening on admission). Action on HAI was also embedded into the Scottish Patient Safety Programme, a national Collaborative aimed at improving patient safety. From the outset, there was thus a strong emphasis on national leadership. 


\subsubsection{Target-setting}

Starting in 2008, the HAI Taskforce recommended the introduction of a national HEAT target on Staphylococcus aureus bacteraemia (SABs, including MRSA and MSSA), based on the knowledge at that time that SABs represented a dominant cause of infection. A HEAT target on CDI followed in 2009, once baseline data from mandatory surveillance was available. Targets are proposed by a subgroup of the HAI Taskforce whose membership includes key professional groups (infection control managers, medical directors, and microbiologists employed by Boards). Proposals are passed to the Scottish Government for decision. While the Scottish Government thus retains the responsibility for setting targets (reflecting the hierarchist logic), proposals are initiated by the stakeholders who will implement them (reflecting the experimentalist logic).

Target values, however, were derived from technical information rather than consensus; reflecting hierarchist ideas. Initially, targets aimed at a 30 percent reduction of HAIs over a five-year period. This was based on a seminal study on the prevention of nosocomial infection in the United States (Haley et al., 1985) which had found that a third of hospital infections was avoidable with a defined set of interventions including surveillance, having trained infection control staff, and a system for reporting infection rates to practising surgeons. Although this study came from a different context, it seemed "the best evidence and reference point at the time of potential for prevention" (HAI Taskforce representative). 
Although an ideal rate is known for HAI (zero infections), uncertain effect sizes of interventions make it hard to ascertain what levels of quality are feasible in practice. With comparable data becoming available from standardised reporting from the United Kingdom and similar European health systems, since 2011 levels of achievement are determined by 'best-in-class' benchmarking. In this system, the Government seeks to infer an attainable level of quality for NHS Boards from the best performers within Scotland and abroad. However, a key challenge was the choice of threshold. As a manager from a poorer performing Board highlighted: “We argued that the lowest observed rate would not be achievable for all (...) given differences in baseline performance between Boards". Following consultations with Boards, the HAI Taskforce thus agreed on the roughly 75 th percentile of the distribution of HAI rates as the minimum target. Those performing better were expected to continue to improve to prevent regression towards this minimum target.

\subsubsection{Implementation and accountability: the challenge of community- acquired infections}

Since Boards have integrated responsibility for acute, primary and community care, the national target includes all cases of HAI regardless of where they have been acquired. Boards' actions have traditionally focused on hospitals: LDPs over the past years emphasise the education of hospital staff to prevent the transmission of infections. Implementation has focussed on national standards of practice and 'care-bundles', which consist of a standardised set of actions health professionals are expected to follow to prevent infections. While the local 
implementation of these measures required, as interviewees commented, much discussion and testing with local staff (reflecting an experimentalist orientation), standards of practice were defined at the national level and provided common definitions of what constitutes "appropriate care" (reflecting a hierarchist orientation).

However, while significant reductions in HAI have led to increasingly stringent targets consistent with the "best-in-class" approach, Boards' LDPs record challenges from a rising proportion of community-acquired infections (CA-HAIs; defined as infections that develop within 48 hours after patient admission to hospital). In interviews, local managers commented that, from their experience, CA-HAIs were considerably harder to prevent than hospital-acquired HAIs because causal pathways were frequently unknown. As an infection control manager explained: "Hospitals have clear physical and managerial boundaries (...) but in the community, we often do not know where infections come from". Mentioned by three Boards in 2007/08, by 2013/14, all Boards identified CAHAIs as a key risk to meeting national targets. For instance, NHS Tayside's LDPs record that by 2013/14 about 50 percent of SABs were present on admission to hospital, an increase from about 22 percent of SABs in 2006/07.

In analysing national and local responses to this development, two major themes emerge. First, despite a changing problem frame, there appeared to be continuity. According to local LDPs, between 2009/10 and 2013/14, all Boards maintained their focus on hospitals in controlling HAIs. As a local manager explained: "We must keep HAIs on the agenda in hospitals, not shift all attention 
to the community (...) to sustain the successes we have seen". Similarly, national guidance on infection control has been reaffirmed.

Second, however, there appeared to be an increasing emphasis on other approaches to implementation and accountability. This is reflected in the role ascribed to central-local dialogue. As an infection control manager put it: "There has always been some dialogue with Government representatives about infection rates (...) but understanding the causes has become more important with the growing proportion of community-acquired infections". A recent and notable manifestation of this dialogue - which is not documented in the LDPs, but emerged in the interviews - was that Scottish Government leads have started to regularly attend local HAI meetings and share experiences from other Boards. As a local manager explained: “We were struggling with community-acquired infections and the Government teams said to us, 'you might speak to Board $x$ and $y$ about this' (...) this was not a panacea but it was a start”.

A related development concerns the diffusion of tools which - unlike the aforementioned standards of practice - do not prescribe desirable behaviour but rather offer an analytic process. A pertinent example is the use of root-cause analysis (RCA), intended to trace back infections to their initial source and, thus, understand the onset of CA-HAIs. In 2009/10, three Boards reported using RCA in their LDPs. By 2013/14, eleven Boards had taken up RCA. As a consequence, several Boards have started to reach out beyond hospitals towards identifed high-risk settings such as care homes and to engage general practitioners and district nurses in efforts to tackle CA-HAIs. 


\subsubsection{Conclusion}

The perception of HAI as an issue where national standards where both feasible and desirable resulted in centrally determined targets; reflecting a hierarchist orientation. Nevertheless, Boards were consulted and their feedback was acted upon in the specification of target values. This implies the experimentalist concept of joint target-setting between central and local organisations. Implementation has focused on the more hierarchist notion of standardised interventions. However, the reframing of the boundaries of the problem from hospitals to the wider community led to more learning-oriented approaches to implementation and accountability. This can be interpreted as a partial transformation towards experimentalism.

\subsection{Care for older people: the quest for the right 'balance'}

\subsubsection{Policy context}

Shifting care out of hospitals into the community became a key policy focus in 2005, when the Scottish Government launched the Unscheduled Care Collaborative to reduce emergency admissions especially among older people. The Collaborative framework (Scottish Executive, 2005, p.3) set out the principle that: 'change will not be delivered by issuing guidance and directives (...) one size does not fit all. Solutions must meet local need and circumstance and more importantly actively engage staff'. The Government's (2009a) strategic 
framework Shifting the balance of care re-emphasised shifting the location of care (outside hospitals), its focus (from acute to preventive care) and responsibility for its delivery (involving non-medical professionals, patients and carers). These concepts were affirmed in successive policies. Thus, from the outset, policy discourse emphasised local diversity and stakeholder engagement.

\subsubsection{Target-setting}

To serve as strategic measure in support of these policies, in 2006, a HEAT target on reducing multiple re-admissions to hospital for people aged 65 and over was introduced. After the usual three-year cycle, a national stakeholder event including Government officials, clinicians, service users and Boards concluded that some admissions might be unavoidable. 'Clinicians were concerned this target would create a perverse incentive to prevent even necessary admissions (...) based on that feedback, the target was reformulated' (clinical lead). In 2009, a target to reduce emergency bed days for people aged 65 (later narrowed to those aged 75) and over was introduced to clarify the underlying policy ambition: 'The target is about minimising the time spent in hospital for older people (...) patient experience of care and health status often suffer as a result of long hospital stays' (medical director).

The Government agreed levels of achievement bilaterally with each Board, because imposing a single national target was perceived as "untenable due to local variations in the availability of community care, socio-demographic 
composition, and previous reductions in emergency bed days" (Government official).

Experimentalism would suggest that setting targets through dialogue requires a mutual interest in obtaining challenging yet feasible targets. Since HEAT targets are publicly reported and frequently cited to underpin political achievements, one would expect the Scottish Government to have an interest in targets that can be met. However, emergency care puts increasing strain on the NHS budget and rising demand due to demographic changes challenges the Government's pledge to protect universal coverage (Barbour et al., 2014). This has led to a perception that "the situation is unsustainable and there is a real need to reorient health services" (Government official), suggesting a commitment to move beyond merely symbolic targets. The incentive for Boards to identify a credible trajectory was, according to our respondents, both improved patient experience and financial sustainability, which is heavily scrutinised by ministers, Audit Scotland and the Scottish Parliament. The Joint Improvement Team (JIT; a partnership involving the Scottish Government, NHSScotland, the Convention of Scottish Local Authorities (COSLA), and the Third, Independent and Housing sectors) helped to build this argument: JIT provided Boards with estimates of future needs for hospital beds given demographic projections to show how reducing bed days now would mitigate the creation of new hospital beds in the future.

The national target of achieving a 12 percent reduction in emergency bed days between 2009/10 and 2014/15 was derived from the aggregation of Board- 
specific targets. These ranged from 0 percent (for Boards with a relatively low rate of bed days who felt further reductions were not feasible) to about 20 percent over a five-year period (in Grampian, where larger-scale service redesign was under development). Both national and local respondents perceived the process as dialogical rather than adversarial:

'We cannot just set the trajectory as we like (...) we look at our historical data and suggest what we can do (...) then the Government says "we think you can do more here" or "you are too ambitious"and then we go back to the data (...) it is a dialogue really' (planning manager).

'Some Boards seemed very ambitious (...) but some also had an ambitious improvement programme so the trajectory was backed up (...) it was a lot about speaking to Boards' (Scottish Government official).

\subsubsection{Implementation and accountability}

Fundamental problems in SBC - and initial differences to HAI - were the limited evidence of effective interventions, local diversity and Boards' partial ownership of targets. These differences appeared to influence the approaches to both implementation and accountability.

Between 2008 and 2011, a national Long-Term Conditions Collaborative provided information about various tools to improve care pathways (e.g. predictive modelling, anticipatory care plans and intermediate models of care) 
and sought to support NHS Boards in adapting relevant tools to their own local contexts (The Scottish Government, 2009b). In 2010, the 10-year programme Reshaping Care for Older People (The Scottish Government, 2010) established a $£ 70$ million Change Fund to finance innovative projects through local partnerships involving acute, community, third and independent sectors. Some of the resulting local interventions reflect different approaches to essentially the same problem. For instance, since the capacity and quality of social care, funded by local authorities, affects Boards' ability to reduce emergency admissions and achieve timely discharges into community care, all Boards emphasised collaborations with local authorities. However, specific local projects differ in their focus on, amongst others, joint standards for discharge management or expanded access to community and residential care. Other interventions appeared to be driven by context-specific challenges. For instance, rural and remote Boards have put particular emphasis on testing new models of telehealth and telecare.

As Audit Scotland (2014) highlights, the focus on local innovation has struggled with the challenge of ensuring national accountability, in particular with regard to the systematic evaluation of "good practice" and its subsequent "scale-up and spread" in a heterogeneous system. Recently, national organisations have started to address this challenge by promoting national learning events and benchmarking (see e.g. JIT 2014) and the sharing of case studies (QuEST 2014). Local managers we interviewed noted that these case studies were increasingly valued as offering inspiration - rather than prescription - for local action. 


\subsubsection{Conclusion}

Shifting the balance of care for older people was from the outset recognised as an issue of local diversity and uncertainty about effective interventions. As a result, governance focussed on Board-specific targets, innovative models of care and local partnerships, and attempts to share learning. This approach reflects core principles associated with experimentalist governance.

\section{Discussion}

Prompted by the limits of a hierarchist approach to setting targets for policy issues whose 'ideal' ends and means for change are ambiguous, we have examined whether complementary use of hierarchist and experimentalist ideas is possible.

Returning to our research questions, the findings suggest the following. First, hierarchist and experimentalist elements can be shown to exist in the same performance management regime (Table 4). Experimentalism adds distinct aspects to target-setting, implementation, and accountability that are missing from a purely hierarchist approach (Table 1). In Scotland, this has led to a system where: central and local actors contribute to setting targets; central bodies support local attempts to implement change; and local actors are held accountable both for processes and for results. This suggests a complementary role of experimentalism (Fossum, 2012). Nevertheless, there is also some evidence of tension between the logics. This is illustrated by the ambivalent 
perception of Government performance support teams with their dual mandate for central control and local support.

Second, while both logics co-existed at the HEAT system level, their relative emphasis differed between policy issues and also over time within a policy issue. Where targets were informed by the vision of an optimal balance between community and hospital care and means for change were ambiguous (care for older people; Table 2), governance styles reflected experimentalist ideas more strongly. Where ends and means were known initially (HAI; Table 2), targets followed a more hierarchist logic. When the rise of community-acquired infections decreased clarity about effective interventions, the ideal level of HAI (zero) and the model for target-setting remained constant. However, a more learning-oriented approach to implementation and accountability ensued (Table 4). This can be interpreted as a partial drift in governance style to the experimentalist realm (Figure 4).

Figure 4 about here

The main implication of these findings is that the distinct combination of governance logics can be adapted on a target-by-target basis. Thinking of hierarchism and experimentalism as a property of the performance management system as a whole may be analytically too coarse (from a research perspective) and neglect opportunities that arise from drawing on both logics (from a policy perspective). As this study shows, it is important to look deeper at differences between policy issues and at dynamics over time. 
Our study setting, the Scottish HEAT target system, was chosen explicitly because we expected it to be receptive to complementarity between hierarchism and experimentalism. Its socio-historical and administrative context is characterised by longstanding collaboration between central and local organisations alongside a well-developed central-local accountability relationship (McDermott et al., 2015). Our finding that it is possible to combine experimentalism and hierarchism may thus not be easily transferable to systems which do not meet these conditions. In countries where administrative competencies are dispersed between actors, hierarchist target-setting is less likely to play a key role and an experimentalist governance logic may be the only feasible approach to set targets at all. In turn, however, experimentalism is likely to flourish only if it is possible to develop the infrastructure and willingness to encourage local freedom to innovate, with requisite financial and managerial support, and then share experiences across the system.

Overall, our findings highlight the need for policy and research to reconsider the strict separation between 'measurement for improvement' and 'measurement for accountability' (Solberg et al., 1997, Freeman, 2002, Davies, 2005). The experiences from Scotland lead us to conclude that both purposes can co-exist within a system. Setting targets does not have to end up in 'targets and terror' but may combine stakeholder engagement with accountability for results. This is an important contribution to existing research which found the hierarchist approach to target-setting, focussed on accountability for results, and the learning- and engagement-oriented approach to target-setting, which reflects experimentalist ideas, in separate countries but not in the same system (Ernst et 
al. 2008). We have shown that the nature of policy issues and changes therein over time are important conditions for synergies between governance logics. Future research might further explore the enabling conditions for and outcomes of combining multiple logics of target governance within different institutional contexts. 


\section{References}

Audit Scotland (2013). NHS financial performance 2012/13, Edinburgh, Audit Scotland. Audit Scotland (2014). Reshaping care for older people, Edinburgh, Audit Scotland.

Barbour, J., Morton, A. \& Schang, L. (2014). The Scottish NHS: meeting the financial challenge ahead. Fraser of Allander Economic Commentary, 38, 126-146.

Barzelay, M. (1992). Breaking through Bureaucracy: A New Vision for Managing in Government, Berkeley, CA, University of California Press.

Bevan, G. (2010). Performance Measurement of "Knights" and "Knaves": Differences in Approaches and Impacts in British Countries after Devolution. Journal of Comparative Policy Analysis, 12, 33-56.

Bevan, G. \& Hood, C. (2006). What's measured is what matters: Targets and gaming in the English public health care system. Public Administration, 84, 517-538.

Bevan, G., Karanikolos, M., Exley, J., Nolte, E., Connolly, S. \& Mays, N. (2014). The four health systems of the United Kingdom: how do they compare?, London, The Health Foundation and The Nuffield Trust.

Blackman, T., Elliott, E., Greene, A., Harrington, B., Hunter, D., Marks, L., McKee, L., Smith, K. \& Williams, G. (2009). Tackling Health Inequalities in Post-Devolution Britain: Do Targets Matter? Public Administration, 87, 762-778.

Carter, N. (1989). Performance Indicators - Backseat Driving or Hands Off Control. Policy and Politics, 17, 131-138.

Commission on the future delivery of public services (2011). Report on the Future Delivery of Public Services by the Commission chaired by Dr Campbell Christie, Cheadle Heath, APS Group Scotland.

Davies, H. (2005). Measuring and reporting the quality of health care: issues and evidence from the international research literature, Edinburgh, NHS Quality Improvement Scotland.

Eberlein, B. (2010). Experimentalist Governance in the European Energy Sector. In: Sabel, CF., Zeitlin, J. (eds). Experimentalist Governance in the European Union. Oxford: OUP.

Ernst, K., Wismar, M., Busse, R. \& McKee, M. (2008). Improving the Effectiveness of Health Targets. In: Wismar, M., McKee, M., Ernst, K., Srivastava, D. \& BUSSE, R. (eds.) Health Targets in Europe: Learning from experience. Copenhagen: World Health Organisation, on behalf of the European Observatory on Health Systems and Policies.

Farrar, S., Harris, F., Scott, T. \& McKee, L. (2004). The Performance Assessment Framework: experiences and perceptions of NHSScotland, A Report to the Analytical Service Division, Directorate of Performance Management and Finance, Scottish Executive Health Department.

Fierlbeck, K. (2014). The changing contours of experimental governance in European health care. Social Science \& Medicine, 108, 89-96.

Fischer, M. \& Ferlie, E. (2013). Resisting hybridisation between modes of clinical risk management: Contradiction, contest, and the production of intractable conflict. Accounting, Organisations and Society, 38, 30-49.

Fossum, J. E. (2012). Reflections on experimentalist governance. Regulation \& Governance, 6, 394-400.

Freeman, T. (2002). Using performance indicators to improve health care quality in the public sector: a review of the literature. Health Services Management Research, $15,126-37$ 
Goddard, M., Mannion, R. \& Smith, P. (2000). Enhancing performance in health care: a theoretical perspective on agency and the role of information. Health Economics, 9, 95-107.

Greer, S. (2004). Territorial Politics and Health Policy. Manchester: Manchester University Press.

Guest, G., Bunce, A. \& Johnson, L. (2006). How many interviews are enough? An experiment with data saturation and variability. Field Methods, 18, 59-82.

HAI Taskforce (2008). Healthcare Associated Infection Taskforce Delivery Plan April 2008 to March 2011, http://www.scotland.gov.uk/Publications/(2008/03/07110818/0 [5 April 2014].

Haley, R. W., Culver, D. H., White, J. W., Morgan, W. M., Emori, T. G., Munn, V. P. \& Hooton, T. M. (1985). The Efficacy of Infection Surveillance and Control Programs in Preventing Nosocomial Infections in United-States Hospitals. American Journal of Epidemiology, 121, 182-205.

Hocepied, C. \& A. de Streel (2005). The ambiguities of the European electronic communications regulation. In: E.J. Dommering and N.A.N.M. van Eijk (eds), The Round Table Expert Group on Telecommunications Law, University of Amsterdam, pp. 139-190.

Hood, C. (2007). Public service management by numbers: Why does it vary? Where has it come from? What are the gaps and the puzzles? Public Money \& Management, 27, 95-102.

Hood, C. \& Jackson, M. (1994). Keys for Locks in Administrative Argument. Administration \& Society, 25, 467-488.

Hsieh, H. F. \& Shannon, S. E. (2005). Three approaches to qualitative content analysis. Qual Health Res, 15, 1277-88.

Jacobs, R., Martin, S., Goddard, M., Gravelle, H. \& Smith, P. (2006). Exploring the determinants of NHS performance ratings: lessons for performance assessment systems. Journal of Health Services Research \& Policy, 11, 211-217.

JIT (Joint Improvement Team) (2014). Annual Report 2013/14, Edinburgh, Joint Improvement Team.

Johnston, L., Lardner, C. \& Jepson, R. (2008). Overview of evidence relating to shifting the balance of care: a contribution to the knowledge base, Edinburgh, Scottish Government Social Research.

Lawton, A., Mckevitt, D. \& Millar, M. (2000). Coping with ambiguity: Reconciling external legitimacy and organisational implementation in performance measurement. Public Money \& Management, 20, 13-19.

Mays, N. (2006). Use of Targets to Improve Health System Performance: English NHS Experience and Implications for New Zealand, Wellington, New Zealand Treasury.

Mcdermott, A., Hamel, L., Steel, D., Flood, P. \& McKee, L. (2015). Hybrid healthcare governance for improvement? Combining top-down and bottom-up approaches to public sector regulation. Public Administration 93(2), 324-344

NHS Tayside (2011). LDP Risk Management Plan 2011/12, Dundee, NHS Tayside.

Noonan, K. G., Sabel, C. F. \& Simon, W. H. (2009). Legal Accountability in the ServiceBased Welfare State: Lessons from Child Welfare Reform. Law and Social Inquiry-Journal of the American Bar Foundation, 34, 523-568.

Patton, M. (2002). Qualitative research \& evaluation methods, Thousand Oaks, Sage

Pires, R. (2011). Beyond the fear of discretion: Flexibility, performance, and accountability in the management of regulatory bureaucracies. Regulation \& Governance, 5, 43-69. 
Pollitt, C., Harrison, S., Dowswell, G., Jerak-Zuiderent, S. \& Bal, R. (2010). Performance Regimes in Health Care: Institutions, Critical Junctures and the Logic of Escalation in England and the Netherlands. Evaluation, 16, 13-29.

Power, M. (1999). The Audit Society: Rituals of Verification, Oxford, Oxford University Press.

QUEST (Quality AND Efficiency Support Team) (2014). Annual Report (2013: Reporting on the Quality and Efficiency Support Team, Edinburgh, The Scottish Government.

Rittel, H. W. J. \& Webber, M. M. (1973). Dilemmas in a General Theory of Planning. Policy Sciences, 4, 155-169.

Sabel, C. (2004). Beyond principal-agent governance: experimentalist organisations, learning and accountability. In: Engelen, E. \& Sie Dhian Ho, M. (eds.) De staat van de democratie. Democratie voorbij de staat. Amsterdam: Amsterdam University Press, pp. 173-196.

Sabel, C. \& Zeitlin, J. (2012). Experimentalist Governance. In: Levi-Faur, D. (ed.) The Oxford Handbook of Governance. Oxford: Oxford University Press, pp. 169-183.

Sabel, C. F. \& Zeitlin, J. (2008). Learning from difference: The new architecture of experimentalist governance in the EU. European Law Journal, 14, 271-327.

Scottish Executive (2005). The Unscheduled Care Collaborative Programme, Edinburgh, Scottish Executive.

Smith, P. (1995). On the unintended consequences of publishing performance data in the public sector. International Journal of Public Administration, 18, 277-310.

Smith, P. C. \& Busse, R. (2010). Learning From the European Experience of Using Targets to Improve Population Health. Preventing Chronic Disease, 7(5): A102.

Solberg, L. I., Mosser, G. \& Mcdonald, S. (1997). The three faces of performance measurement: Improvement, accountability and research. Joint Commission Journal on Quality Improvement, 23, 135-147.

Steel, D. \& Cylus, J. (2012). United Kingdom (Scotland): Health system review. Health Systems in Transition, 14, xv-xxii, 1-150.

The Scottish Government (2009a). Improving Outcomes by Shifting the Balance of Care, Edinburgh, The Scottish Government.

The Scottish Government (2009b). Long Term Conditions Collaborative. Programme 2008-2011, Edinburgh, The Scottish Government.

The Scottish GovernmenT (2010). Reshaping Care for Older People. A Programme of Change 2011 -2021, Edinburgh, The Scottish Government.

Wismar, M., McKee, M., Ernst, K., Srivastava, D. \& busse, R. (2008). Health Targets in Europe: Learning from experience, Copenhagen, World Health Organisation, on behalf of the European Observatory on Health Systems and Policies. 


\section{Tables and Figures}

Table 1 Hierarchist and experimentalist assumptions about performance targets

\begin{tabular}{|c|c|c|}
\hline $\begin{array}{l}\text { Assumptions } \\
\text { regarding }\end{array}$ & Hierarchism & Experimentalism \\
\hline $\begin{array}{l}\text { Ambiguity about } \\
\text { ends: } \\
\text { Target-setting }\end{array}$ & $\begin{array}{l}\text { Central government has a legitimate mandate to set } \\
\text { targets for subordinate administrations. }\end{array}$ & $\begin{array}{l}\text { Knowledge about goals is contested, provisional and distributed between } \\
\text { central and local actors. Therefore, target-setting should be a joint process } \\
\text { between central and local actors. }\end{array}$ \\
\hline $\begin{array}{l}\text { Ambiguity about } \\
\text { means: } \\
\text { Implementation of } \\
\text { targets }\end{array}$ & $\begin{array}{l}\text { - Means for change are available to local agents. } \\
\text { - The state designs contracts, incentivising agents to } \\
\text { meet the targets and controlling the effects of } \\
\text { asymmetric information about the effort of agents. }\end{array}$ & $\begin{array}{l}\text { - Means for change are ambiguous. } \\
\text { - The state provides support, encourages mutual learning and spread of } \\
\text { good practice. }\end{array}$ \\
\hline Accountability & $\begin{array}{l}\text { Inspection of results and application of rewards and } \\
\text { punishments. }\end{array}$ & $\begin{array}{l}\text { Inspection of validity of processes: frontline organisations review and } \\
\text { explain the choices they make for running a programme. }\end{array}$ \\
\hline
\end{tabular}

Sources: authors' display based on Sabel and Zeitlin (2012); Pires (2011). 
Table 2 Case studies

\begin{tabular}{|c|c|c|c|}
\hline Policy issue & End (ideal) & Means & Targets (examples) \\
\hline $\begin{array}{l}\text { Healthcare- } \\
\text { associated } \\
\text { infections } \\
\text { (HAI) }\end{array}$ & $\begin{array}{l}\text { Zero } \\
\text { infections }\end{array}$ & $\begin{array}{l}\text { Relatively good } \\
\text { evidence of } \\
\text { effective } \\
\text { interventions } \\
\text { (e.g. Haley et al., } \\
\text { 1985) }\end{array}$ & $\begin{array}{l}\text { Reduce by } 2012 / 13 \text { NHS Boards' } \\
\text { staphylococcus aureus bacteriamia } \\
\text { (including MRSA) cases to } 0.26 \text { or less } \\
\text { per } 1,000 \text { acute occupied bed days; } \\
\text { and the rate of Clostridium difficile } \\
\text { infections in patients aged } 65 \text { and } \\
\text { over to } 0.39 \text { cases or less per } 1,000 \\
\text { total occupied bed days }\end{array}$ \\
\hline $\begin{array}{l}\text { Shifting the } \\
\text { balance of } \\
\text { care for } \\
\text { older } \\
\text { people } \\
\text { (SBC) }\end{array}$ & $\begin{array}{l}\text { Unknown } \\
\text { balance } \\
\text { between } \\
\text { hospital and } \\
\text { community } \\
\text { care }\end{array}$ & $\begin{array}{l}\text { Service redesign } \\
\text { - complex and } \\
\text { little evidence } \\
\text { (Johnston et al., } \\
\text { 2008) }\end{array}$ & $\begin{array}{l}\text { Reduce the rate of emergency } \\
\text { inpatient bed days for people aged } 75 \\
\text { and over per } 1,000 \text { population, by at } \\
\text { least } 12 \% \text { between } 2009 / 10 \text { and } \\
2014 / 15\end{array}$ \\
\hline
\end{tabular}


Table 3 Data sources

\section{Data source}

National policy documents

112 Local Delivery Plans (from 2006/07 over seven years for all Boards)

31 semi-structured interviews lasting 35-90 minutes

National level: 9 with Scottish Government officials and national organisations: Quality and Efficiency Support Team, HAI Taskforce, Health Protection Scotland, Joint Improvement Team

Local level: 22 with senior and middle managers from NHS Boards: chief executives, heads of performance management, medical directors, infection control managers, and operational managers

- 8 of 14 Boards: Greater Glasgow and Clyde; Borders; Tayside; Dumfries and Galloway; Shetland; Grampian; Forth Valley; Lothian

- 2-4 interviews per Board to obtain different perspectives

\section{Rationale}

Policy context and developments

Historical, public documents agreed with the Government in which Boards set out risks and management strategies for each target Perceptions not addressed in public documents 
Table 4 Hierarchist and experimentalist governance elements in the Scottish HEAT target system

\begin{tabular}{|c|c|c|c|c|}
\hline & \multicolumn{2}{|c|}{ System level: HEAT framework } & \multirow{2}{*}{$\begin{array}{l}\text { Policy issue level } \\
\text { HAI }\end{array}$} & \multirow[b]{2}{*}{ SBC } \\
\hline & $\begin{array}{c}\text { Reflects } \\
\text { hierarchist logic }\end{array}$ & $\begin{array}{c}\text { Reflects } \\
\text { experimentalist logic }\end{array}$ & & \\
\hline \multirow[t]{2}{*}{ Target-setting } & $\begin{array}{l}\text { The Government decides } \\
\text { on target indicators. }\end{array}$ & $\begin{array}{l}\text { Boards and service user } \\
\text { groups, and national } \\
\text { groups with Board } \\
\text { representatives can } \\
\text { propose and/or } \\
\text { comment on proposed } \\
\text { indicators. }\end{array}$ & $\begin{array}{l}\text { Target values were set centrally, } \\
\text { reflecting a hierarchist orientation. }\end{array}$ & $\begin{array}{l}\text { Target values were developed } \\
\text { through dialogue, reflecting an } \\
\text { experimentalist orientation. }\end{array}$ \\
\hline & & $\begin{array}{l}\text { Targets are revised after } \\
\text { a three-year cycle. }\end{array}$ & & \\
\hline Implementation & $\begin{array}{l}\text { LDPs are negotiated as } \\
\text { 'contract' between } \\
\text { Government and Boards. }\end{array}$ & $\begin{array}{l}\text { LDPs serve to identify } \\
\text { risks and management } \\
\text { strategies locally. }\end{array}$ & $\begin{array}{l}\text { National guidance defines standards } \\
\text { for local action, reflecting a } \\
\text { hierarchist orientation. } \\
\text { With the rise of CA-HAIs: Emphasis } \\
\text { on dialogue and networks to share } \\
\text { good practice, collaborative research } \\
\text { and involvement of community } \\
\text { health professionals, reflecting an } \\
\text { experimentalist orientation. }\end{array}$ & $\begin{array}{l}\text { Local innovation was funded } \\
\text { through the Change Fund and } \\
\text { is increasingly shared through } \\
\text { case studies, reflecting an } \\
\text { experimentalist orientation. }\end{array}$ \\
\hline Accountability & $\begin{array}{l}\text { Target achievement is } \\
\text { assessed at Annual } \\
\text { Reviews and publicly } \\
\text { reported. }\end{array}$ & $\begin{array}{l}\text { Diagnostic monitoring } \\
\text { throughout the year } \\
\text { serves to identify and } \\
\text { remedy problems. }\end{array}$ & $\begin{array}{l}\text { With the rise of CA-HAIs: Emphasis } \\
\text { on root-cause analysis and } \\
\text { inspection of local clinical processes } \\
\text { reflecting an experimentalist } \\
\text { orientation. }\end{array}$ & \\
\hline
\end{tabular}


Figure 1 Ambiguity over goals and means in relation to governance style 